\title{
Experience of a serious life event increases the risk for childhood type 1 diabetes: the ABIS population-based prospective cohort study
}

\author{
Maria Nygren • John Carstensen • Felix Koch • \\ Johnny Ludvigsson • Anneli Frostell
}

Received: 23 October 2014 / Accepted: 13 February 2015 / Published online: 14 April 2015

(C) Springer-Verlag Berlin Heidelberg 2015

\begin{abstract}
Aims/hypothesis The aim of this study was to prospectively investigate whether psychological stress during childhood may be a risk factor for manifest type 1 diabetes.

Methods The All Babies In Southeast Sweden (ABIS) study invited all families with babies born between 1 October 1997 and 30 September 1999 in southeast Sweden to participate. Our study subsample includes 10,495 participants in at least one of the data collections at $2-3,5-6,8$ and $10-13$ years of age not yet diagnosed with type 1 diabetes at inclusion; 58 children were subsequently diagnosed. Age at diagnosis was obtained from the national register SweDiabKids in 2012. Family psychological stress was measured via questionnaires given to the parents assessing serious life events, parenting stress, parental worries and the parent's social support.

Results Childhood experience of a serious life event was associated with a higher risk of future diagnosis of type 1 diabetes (HR 3.0 [95\% CI 1.6, 5.6], $p=0.001$ ) after adjusting for heredity of type 1 diabetes and age at entry into the study. The
\end{abstract}

Johnny Ludvigsson and Anneli Frostell are joint senior authors on this paper.

Electronic supplementary material The online version of this article (doi:10.1007/s00125-015-3555-2) contains peer-reviewed but unedited supplementary material, which is available to authorised users.

M. Nygren $(\bowtie) \cdot J$. Ludvigsson

Division of Pediatrics, Department of Clinical and Experimental

Medicine, Linköping University, 58183 Linköping, Sweden

e-mail: maria.nygren@liu.se

J. Carstensen

Division of Health and Society, Department of Medical and Health

Sciences, Linköping University, Linköping, Sweden

F. Koch · A. Frostell

Division of Psychology, Department of Behavioural Sciences and

Learning, Linköping University, Linköping, Sweden result was still valid when controlling for heredity of type 2 diabetes, size for gestational age, the parents' education level and whether the mother worked at least $50 \%$ of full time before the child's birth (HR 2.8 [95\% CI 1.5, 5.4], $p=$ 0.002 ), and also when childhood BMI was added to the model (HR 5.0 [95\% CI 2.3, 10.7], $p<0.001$ ).

Conclusions/interpretation This first prospective study concluded that experience of a serious life event in childhood may be a risk factor for manifest type 1 diabetes.

Keywords Longitudinal studies - Prospective studies . Psychological stress - Risk factors - Stressful events . Type 1 diabetes mellitus
Abbreviations
ABIS All Babies In Southeast Sweden
SLE Serious life event
SPSQ Swedish Parenthood Stress Questionnaire

\section{Introduction}

The aetiology behind type 1 diabetes is unknown, but both genetic and environmental factors are involved. It is usually preceded by autoimmune destruction of insulin-producing beta cells in genetically predisposed individuals [1], and several environmental factors such as viral infections [2], dietary habits in infancy [3], birthweight and early weight gain [4], as well as chronic stress [5], have been proposed as risk factors. The incidence among young children is increasing in most countries in the world [6], suggesting that environmental factors need to be examined seriously. 
Psychological stress has long been suggested as an environmental factor [5]. In particular, severe life events during childhood have been studied as a potential risk factor for type 1 diabetes, mainly retrospectively [7-16]. One study examined stress exposure on a group level [17] and one prospective study examined stress early in life [18]. Retrospective reports of stress may be confounded by the onset of diabetes, since it is a very stressful event. As the first prospective study of individuals, the present study aimed to examine whether psychological stress in terms of experiences of serious life events (SLEs), along with parental perception of parenting stress and lack of social support, during the child's first 14 years of life, may be a risk factor for manifest type 1 diabetes.

According to the beta cell stress hypothesis [5], all factors that increase the need for insulin or increase insulin resistance might be risk factors for the development of type 1 diabetes; hence, psychological stress leading to increased stress hormone concentrations may contribute to the disease. Some previous studies have found an association between diabetes and the experience of one or more severe life events for the child before diagnosis $[9,10,14-16]$, but other studies have only found such an association for specific types of life events [11, $13,17]$, or only if the event had been judged as negative for the child [12]. More chaotic family function, but not a lack of parental social support, has been associated with a diagnosis [12].

Based on the beta cell stress hypothesis [5] and previous research, we hypothesised that we would find an increased risk of type 1 diabetes in children with a previous experience of SLEs and in children whose parents reported higher levels of parenting stress, worries or lack of social support.

\section{Methods}

Participants

The All Babies In Southeast Sweden (ABIS) study invited all families with babies born between 1 October 1997 and 30 September 1999 in southeast Sweden to participate. In total, the parents of 16,153 children participated by answering one or more questionnaires. The current study examined data from families participating in at least one of four data collections carried out when the children were between 2 and 14 years of age $(N=10,495)$. Of these, 58 children were diagnosed with type 1 diabetes between 3 and 14 years of age (for details of the sample, see Fig. 1). The inclusion criterion was that the child had not been diagnosed with diabetes when participating for the first time. Due to the time-sensitive measure in the Cox regression model, participants with a missing date of participation were excluded at that specific time point.

\section{Procedure}

After data collection at birth, the families were invited to five data collections when the children were aged $1,2-3,5-6,8$ and 10-13 years, and the current study examined the four latter time points. Data concerning the collection at age 1 year have been reported elsewhere [18]. Data collections at ages 23 and 5-6 years were conducted in association with regular check-ups at well baby clinics. Around $99 \%$ of all Swedish parents bring their children to these check-ups, which are government subsidised. The questionnaire was filled out during the visit or later at home and returned by mail; no reminders were used. In total, 250 clinics were involved. At the 8 year and at part of the 10-13 year data collections, the
Fig. 1 Flow diagram of the study sample, showing the number of total participants and diabetes patients at each data collection point. Apr, April; Sep,

September; Oct, October; T1D, type 1 diabetes

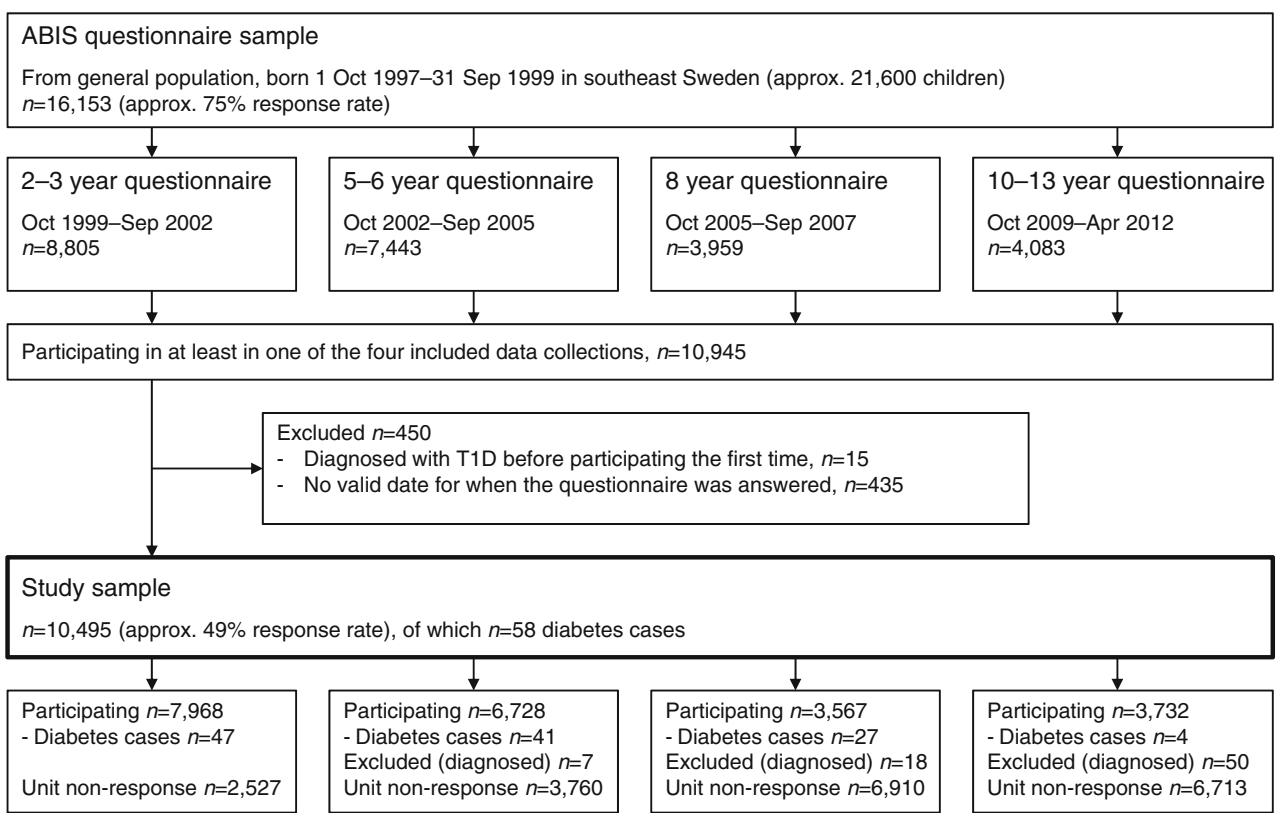


questionnaire was sent home to the parents and returned by mail. One reminder was used for the questionnaire at 1013 years. The other part of the data collection at 10-13 years was conducted in collaboration with schools: the child brought the questionnaire home to the parent, who returned it by mail and no reminders were used. The questionnaire was usually filled out by the mother (age $2-3,96.6 \%$; age 5-6, $91.1 \%$; age $8,89.0 \%$ and age $10-13,84.8 \%$ by the mother only and $6.6 \%$ by the mother and father together). Before giving their consent to participate, the parents received printed and oral information and were offered the chance to see a video concerning the project. Before each new data collection, the parents received new written information and gave continued consent by answering the questionnaire. The ABIS study was approved by the research ethics committees at Linköpings University (Dnr 96-287, Dnr 99-321, and Dnr 03-092) and Lund University (LU 83-97), both in Sweden.

\section{Outcomes}

Identification of diabetes cases and the dates of diagnosis were made on 31 December 2012 from the national register SweDiabKids, where all children in Sweden diagnosed with type 1 diabetes mellitus according to international criteria are registered.

\section{Exposure variables}

Psychological stress in the family Several instruments in the ABIS questionnaires measured different aspects of psychological stress within the family. Simultaneous exposure of stress assessed with these instruments in ABIS has previously been found to be associated with increased levels of cortisol and an altered immune response in the child [19]. The instruments included vary somewhat between the four time points.

SLEs Experiences of stressful, severe or negative life events or, as called in ABIS, SLEs have commonly been assessed by self-reported checklists beginning with the social readjustment rating scale by Holmes and Rahe in 1967 [20]. Coddington applied this scale to children using parents and adolescents as informants [21]. In ABIS, SLEs experienced by the child (SLE-child) were assessed at three time points with the general question 'Has your child been exposed to something which you perceive as a serious life event...' with '... since the child's birth?' in the 5-6 years questionnaire and with '... in the last two years?' in 8 and 10-13 years questionnaire. Each time the question was followed by a checklist (Table 1). A 'yes' for the general question and/or 'yes' for one or more of the items on the checklist was defined as 'any kind of SLE'. The checklist was revised once; hence, comparable broader categories of life events have been constructed to enable longitudinal analyses (Table 1). In order to include other events experienced in the family that may have affected the child we also included SLEs experienced by the parent (SLE-parent) assessed at all four data collections in the same way as for SLE-child but with the question beginning 'Have you been exposed to...'. As for SLE-child, categories of events comparable over time were constructed (Table 1). For all variables of SLE, a 'yes' means that at least one SLE was experienced at some time during childhood before diagnosis.

Parenting stress and worries Parenting stress (i.e. the parent's perception of stress associated with parenthood) was assessed when the children were aged 2-3, 5-6 and 8 years by three (incompetence, spouse relationship problems and role restriction) out of five subscales of the Swedish Parenthood Stress Questionnaire (SPSQ) [22] - a translation and reconstruction of the Parenting Stress Index [23]. Each item was assessed on a Likert scale of 1-6, where higher values indicate more stress. In ABIS, parenting stress has previously been associated with increased levels of saliva cortisol [24].

Parental worries were assessed at all four data collections by the general question 'Have you worried about any of the following...' with '... since the child turned 1 year?' at the 2-3 and 5-6 year questionnaires and '...in the last two years?' at the 8 and 10-13 years questionnaires. The general question was followed by 6-8 items (Likert scale 1-6), each describing an age-appropriate risk such as the child would be harmed, exposed to abuse, not survive, become seriously ill or be bullied at school. A mean value across all items (allowing for one missing value) was calculated, where a higher value indicates more worries.

Parent's social support The quantity and quality of the parent's social support were assessed when the children were aged 5-6 and 10-13 years by a questionnaire derived from Crnic et al [25], which was previously used in Sweden by Östberg and Hagekull [26] and previously described in ABIS by Koch et al [27]. A higher value reflects a smaller social network and more dissatisfaction.

Social isolation as a consequence of parenthood was assessed when the children were aged 2-3 years by the social isolation subscale (seven items) of SPSQ [22], with a higher value indicating more social isolation.

Potential confounding factors

In a previous ABIS study [18], the associations between type 1 diabetes and several factors commonly discussed as risk factors were reported. Only variables with $p<0.05$ or with HR $<0.50$ or $>2.0$ in the previous study were regarded as potential confounders in the current study. These were heredity for type 1 diabetes (referred to as 'heredity'), heredity for type 2 diabetes, size for gestational age (according to the equation from the Swedish National Board of Health and 
Table 1 Checklists of SLEs for the child and parent, distribution of exposure at each data collection point and construction of comparable broader categories between data collections

\begin{tabular}{|c|c|c|c|c|c|}
\hline SLE & Events in checklist & $\begin{array}{l}\text { At } 5-6 \text { years }^{\mathrm{a}}: \\
n(\%)\end{array}$ & Events in checklist & $\begin{array}{l}\text { At } 8 \text { years }{ }^{b}: \\
n(\%)\end{array}$ & $\begin{array}{l}\text { At } 10-13 \text { years }^{\mathrm{b}}: \\
n(\%)\end{array}$ \\
\hline \multicolumn{6}{|l|}{ Child } \\
\hline \multirow[t]{4}{*}{ Death and illness } & 1. Death of relative & $807(12)$ & 1. Death of parent or sibling & $18(1)$ & $52(1)$ \\
\hline & & & 2. Death of grandparent & $310(9)$ & $463(12)$ \\
\hline & & & 3. The child is/have been seriously ill & $23(1)$ & $53(1)$ \\
\hline & & & $\begin{array}{l}\text { 4. Severe illness in the family } \\
\text { (besides the child) }\end{array}$ & $184(5)$ & $320(9)$ \\
\hline \multirow{6}{*}{$\begin{array}{l}\text { New family } \\
\text { structure }\end{array}$} & 2. Parents divorced/separated & $499(7)$ & 5. Parents divorced/separated & $125(4)$ & $136(4)$ \\
\hline & 3. New adult in the family & $215(3)$ & 6. New adult in the family & $109(3)$ & $129(3)$ \\
\hline & $\begin{array}{l}\text { 4. New child in the family } \\
\text { (except biological sibling) }\end{array}$ & $137(2)$ & $\begin{array}{l}\text { 7. New child in the family (non-biological } \\
\text { siblings as well) }\end{array}$ & $203(6)$ & $142(4)$ \\
\hline & & & 8. Shared custody living with both parents & $161(5)$ & $177(5)$ \\
\hline & & & $\begin{array}{l}\text { 9. Single custody but contact with the } \\
\text { other parent }\end{array}$ & $35(1)$ & $47(1)$ \\
\hline & & & $\begin{array}{l}\text { 10. Single custody without regular contact } \\
\text { with the other parent }\end{array}$ & $35(1)$ & $62(2)$ \\
\hline Conflict at home & $\begin{array}{l}\text { 5. Many conflicts between } \\
\text { adults at home }\end{array}$ & $236(4)$ & 11. Many conflicts between adults at home & $111(3)$ & $182(5)$ \\
\hline \multirow{3}{*}{$\begin{array}{l}\text { Intervention by } \\
\text { social services }\end{array}$} & 6. Contact with support family & $22(0.3)$ & 12. Contact with support family & $12(0.3)$ & $11(0.3)$ \\
\hline & $\begin{array}{l}\text { 7. Social support intervention } \\
\text { in the family }\end{array}$ & $22(0.3)$ & 13. Social support intervention in the family & $10(0.3)$ & $32(1)$ \\
\hline & 8. Child in foster care & $6(0.1)$ & 14. Child in foster care & $3(0.1)$ & $6(0.2)$ \\
\hline \multicolumn{6}{|l|}{ Parent } \\
\hline \multirow{5}{*}{$\begin{array}{l}\text { Death, illness } \\
\text { and accidents }\end{array}$} & 1. Death of relative & $1,362(20)$ & 1. Death of partner or child & $14(0.4)$ & $26(1)$ \\
\hline & 2. Severe illness in the family & $660(10)$ & $\begin{array}{l}\text { 2. Death of parent (in } 8 \text { years), death of } \\
\text { parent or sibling (in } 10-13 \text { years) }\end{array}$ & $195(5)$ & $298(8)$ \\
\hline & 3. Severe accident in the family & $138(2)$ & 3. Yourself suffered from serious illness & $69(2)$ & $115(3)$ \\
\hline & & & $\begin{array}{l}\text { 4. Severe illness in the family } \\
\text { (besides yourself) }\end{array}$ & $224(6)$ & $390(10)$ \\
\hline & & & 5. Severe accident in the family & $43(1)$ & $57(2)$ \\
\hline \multirow[t]{3}{*}{ Conflict } & 4. Divorce/separation & $445(7)$ & 6. Divorce/separation & $123(3)$ & $143(4)$ \\
\hline & 5. Exposed to violence & $40(1)$ & 7. Child-care dispute & $32(1)$ & $39(1)$ \\
\hline & & & 8. Exposed to violence & $16(0.4)$ & $14(0.4)$ \\
\hline \multirow[t]{2}{*}{ Unemployment } & 6. Yourself unemployed & $224(3)$ & 9. Yourself unemployed & $97(3)$ & $121(3)$ \\
\hline & 7. Partner unemployed & $124(2)$ & 10. Partner unemployed & $51(1)$ & $95(3)$ \\
\hline Total sample & & $6,728(100)$ & & $3,567(100)$ & $3,732(100)$ \\
\hline
\end{tabular}

${ }^{\text {a }}$ SLEs experienced since the child's birth

${ }^{\mathrm{b}}$ SLEs experienced in the last 2 years

Welfare), parental education in two levels (compulsory/secondary $[\leq 12$ years], or university for at least 1 year [ $>12$ years]), giving four groups when coding both parents together, and mother working $\leq 50 \%$ of full time before the child's birth. Data for these variables were reported in the ABIS questionnaire at the child's birth.

BMI was included as a possible mediating factor because psychological stress in the family has been associated with childhood obesity in ABIS [27]. Height and weight was assessed in the questionnaires at ages $2-3,5-6$ and 8 years.
BMI was calculated and divided into three groups (normal, overweight, obese) according to age-adjusted international standards.

\section{Effect modifiers}

Variables used as possible effect modifiers were heredity for type 1 diabetes $(10.5 \%$ in the family or extended family, missing items were imputed as 'no') and the child's sex (51.8\% boys). 


\section{Characteristics of the study participants}

Characteristics of our study sample are reported in Table 2, with follow-up time in Table 3. Compared with the unselected part of the ABIS cohort, there was a slightly higher chance of being included in our study sample if the mother had a university education or had worked $>50 \%$ of full time before the child was born (electronic supplementary material [ESM] Table 1). Heredity for type 1 diabetes was not found to influence this (ESM Table 1). The proportion of children diagnosed after data collection at age 2-3 years did not differ significantly between the selected and unselected part of the ABIS cohort $(58 / 10,495=5.5 \%$ compared with $30 / 5,658=$ $5.3 \%, z=0.18, p=0.86)$. The proportions of children exposed

Table 2 Characteristics of the selected study sample

\begin{tabular}{|c|c|c|c|c|c|}
\hline \multirow[t]{2}{*}{ Characteristic } & \multicolumn{2}{|c|}{ Study sample } & \multicolumn{2}{|c|}{ Cox regression $^{\mathrm{a}}$} & \multirow[t]{2}{*}{$p$ value } \\
\hline & $n$ & Proportion (\%) & HR & $95 \% \mathrm{CI}$ & \\
\hline \multicolumn{5}{|l|}{ Sex of the child } & \multirow[t]{3}{*}{0.180} \\
\hline Female & 5,058 & 48 & 0.69 & $0.40,1.19$ & \\
\hline Male & 5,437 & 52 & ref & & \\
\hline \multicolumn{5}{|l|}{ Year of birth } & 0.299 \\
\hline 1997 & 1,079 & 10 & 0.72 & $0.28,1.84$ & \multirow[t]{2}{*}{0.497} \\
\hline 1998 & 5,654 & 54 & ref & & \\
\hline 1999 & 3,762 & 36 & 0.62 & $0.33,1.16$ & 0.135 \\
\hline \multicolumn{5}{|l|}{ Heredity for type 1 diabetes } & \multirow[t]{2}{*}{$<0.001$} \\
\hline No relative with type 1 diabetes & 9,391 & 89 & ref & & \\
\hline Type 1 diabetes in the family & 250 & 2 & 12.19 & $6.09,24.37$ & $<0.001$ \\
\hline Type 1 diabetes in the extended family ${ }^{\mathrm{b}}$ & 854 & 8 & 3.30 & $1.62,6.72$ & 0.001 \\
\hline \multicolumn{5}{|l|}{ Heredity for type 2 diabetes } & \multirow[t]{2}{*}{0.619} \\
\hline No relative with type 2 diabetes & 8,875 & 85 & ref & & \\
\hline Type 2 diabetes in the family & 125 & 1 & 1.86 & $0.54,6.42$ & 0.327 \\
\hline Type 2 diabetes in the extended family ${ }^{\mathrm{c}}$ & 1,495 & 14 & 1.05 & $0.51,2.15$ & 0.905 \\
\hline \multicolumn{5}{|l|}{ Size for gestational age (total $n=10,085$ ) } & 0.577 \\
\hline Small & 199 & 2 & 1.00 & $0.14,7.26$ & 1.000 \\
\hline Appropriate & 9,410 & 93 & ref & & \\
\hline Large & 476 & 5 & 0.35 & $0.05,2.51$ & 0.294 \\
\hline \multicolumn{5}{|l|}{ Parental education (total $n=10,122$ ) } & \multirow[t]{2}{*}{0.050} \\
\hline Both parents comp/sec & 5,646 & 56 & ref & & \\
\hline Both parents univ & 1,717 & 17 & 0.72 & $0.30,1.73$ & 0.458 \\
\hline Mother comp/sec, father univ & 885 & 9 & 2.21 & $1.10,4.41$ & 0.025 \\
\hline Father comp/sec, mother univ & 1,874 & 19 & 0.71 & $0.31,1.63$ & 0.424 \\
\hline \multicolumn{5}{|c|}{ Mother working before child's birth (total $n=10,251$ ) } & \multirow[t]{3}{*}{0.868} \\
\hline $0-50 \%$ & 2,597 & 25 & 1.05 & $0.58,1.91$ & \\
\hline $51-100$ & 7,654 & 75 & ref & & \\
\hline \multicolumn{5}{|l|}{ BMI group (time-dependent covariate) ${ }^{\mathrm{c}}$} & \multirow[t]{2}{*}{0.324} \\
\hline Normal & & 84 & ref & & \\
\hline Overweight & & 13 & 1.42 & $0.66,3.06$ & 0.366 \\
\hline Obese & & 3 & 2.19 & $0.67,7.20$ & 0.196 \\
\hline
\end{tabular}

${ }^{\text {a }}$ Cox regression analyses estimating HRs for diagnosis of type 1 diabetes depending on sex, year of birth, the potential confounding factors and BMI. Two analyses are reported. The first includes the variables measured at the child's birth and the follow-up time ranges from birth to age at diagnosis or 31 December 2012 (diabetes cases $n=55$, total $n=9,888$ ). The second analysis adds the child's BMI as a time-dependent covariate, and the follow-up time ranges from age at entry to age at diagnosis or 31 December 2012 (diabetes cases $n=49$, total $n=8,620$ )

${ }^{\mathrm{b}}$ Grandparents or close relative of the child other than mother, father or sibling

${ }^{\mathrm{c}}$ The proportion of study sample is calculated from the frequencies accumulated across all available risk sets because the variable are time dependent. A risk set contains all children still followed and without diabetes (i.e. prior to the time of diagnosis for a child with diabetes)

comp, compulsory; ref, reference category; sec, secondary; univ, university 
Table 3 Age and follow-up time for the study sample
Min, minimum; Max, maximum; Dec, December

\begin{tabular}{|c|c|c|c|c|c|}
\hline \multirow[t]{2}{*}{ Age and follow-up time } & \multirow[t]{2}{*}{$n$} & \multirow[t]{2}{*}{ Proportion (\%) } & \multicolumn{3}{|c|}{ Age (years) } \\
\hline & & & Mean & Min & Max \\
\hline Age at entry & & & 3.8 & 1.3 & 13.9 \\
\hline Entry at $2-3$ years & 7,968 & 76 & 2.7 & 1.3 & 4.7 \\
\hline Entry at 5-6 years & 1,557 & 15 & 5.4 & 3.9 & 6.7 \\
\hline Entry at 8 years & 536 & 5 & 7.9 & 6.7 & 9.5 \\
\hline Entry at $10-13$ years & 434 & 4 & 12.0 & 10.2 & 13.9 \\
\hline \multicolumn{6}{|l|}{ Age at exit } \\
\hline Diabetes cases (at diagnosis) & 58 & 0.6 & 9.8 & 3.5 & 14.4 \\
\hline Censored cases (at 31 Dec 2012) & 10,437 & 99 & 14.3 & 13.3 & 15.3 \\
\hline \multicolumn{6}{|l|}{ Follow-up time in years (from entry) } \\
\hline Diabetes cases (to diagnosis) & 58 & 0.6 & 6.5 & 0.4 & 11.3 \\
\hline Censored cases (to 31 Dec 2012) & 10,437 & 99 & 10.5 & 1.0 & 13.2 \\
\hline
\end{tabular}

to family psychological stress are reported in Table 4 and ESM Table 2. Due to item non-response and measuring at different time points, the total $N$ for each of the variables varies between 7,457 and 10,128.

\section{Statistical methods}

Cox proportional hazard regression with time-dependent covariates (IBM SPSS Statistics Version 21 Release 21.0.0.0; IBM, Armonk, NY, USA) estimating HRs was used to address the main aim. Follow-up time ranges from time of entry (i.e. age when participating in the first of the four follow-ups) to time at diagnosis for diabetes cases or to 31 December 2012 for censored cases. Since the children were of different ages at entry, all analyses were adjusted for age at entry. All variables assessing family psychological stress more than once were regarded as time-dependent covariates. Therefore, the value of each of these variables was updated when follow-up time passed each time of participation in a new data collection; if missing/not participating at the following data collection, the value remained valid until next participation or time of diagnosis/censor. However, a 'yes' response concerning SLE remained from the time it was registered to the end of the study period, i.e. it was not updated to a 'no' from a subsequent data collection.

In order to examine the contribution of each stress variable separately and to avoid effects of multicollinearity, one Cox regression analysis was performed per exposure variable. All analyses were adjusted for heredity for type 1 diabetes. All variables with $p<0.05$ were tested with effect modifiers one at a time. Finally, analyses adjusted for all potential confounders were performed for all variables with $p<0.05$ in previous analyses. Adding the potential confounders reduced the number of diabetes cases due to missing data; therefore, this was not done in the initial analyses.

\section{Results}

Main results

The experience of an SLE by the child as well as by the parent at any time in childhood was associated with a higher risk of a subsequent diagnosis of type 1 diabetes after adjusting for heredity and age at entry into the study, as well as after adjusting for all potential confounders (Table 4). None of the exposure variables capturing the parent's perception of parenting stress, parental worries or social support were found to significantly associate with subsequent diagnosis after adjusting for heredity and age at entry (ESM Table 2).

We further investigated whether the association between SLE and type 1 diabetes could possibly be explained by the child's BMI. After adjustment for BMI groups, included as a time-dependent covariate in the models, the associations between childhood SLE and diabetes risk remained (Table 4).

\section{Effects of different exposures of SLEs}

Both SLEs including death and illness experienced by the child and SLEs including death, illness and accidents experienced by the parent were associated with a higher risk of diagnosis after adjusting for heredity and age at entry into the study, and remained so after adjusting for all potential confounders as well as BMI (Table 4). To find out whether the SLE 'the child is/has been seriously ill' contributes heavily to the association, Cox regression was performed with this particular event excluded from death/illness. The result remained significant (HR 2.25 [95\% CI 1.16, 4.36], $p=0.017$ ).

The subcategories of SLE including divorce, i.e. 'new family structure' for the child and 'conflict' for the parent, were both associated with a higher risk of diagnosis (Table 4). However, these associations did not remain significant after adjusting for all potential confounders and BMI (Table 4). 
Table 4 Cox regression analyses with time-dependent exposure variables estimating HRs for the diagnosis of type 1 diabetes depending on different experiences of SLEs ${ }^{\mathrm{a}}$

\begin{tabular}{|c|c|c|c|c|c|c|c|c|}
\hline \multirow[t]{3}{*}{ SLE } & \multicolumn{2}{|l|}{ Exposed to SLE } & \multicolumn{6}{|c|}{ Cox regression analyses } \\
\hline & \multirow[t]{2}{*}{$\begin{array}{l}\text { Diabetes cases }{ }^{\mathrm{b}} \\
(n(\%))\end{array}$} & \multirow[t]{2}{*}{$\begin{array}{l}\text { Study sample } \\
(\%)\end{array}$} & \multicolumn{2}{|c|}{$\begin{array}{l}\text { Adjusted for heredity and } \\
\text { age at entry }\end{array}$} & \multicolumn{2}{|c|}{$\begin{array}{l}\text { Adjusted for potential } \\
\text { confounding factors }^{\mathrm{d}}\end{array}$} & \multicolumn{2}{|c|}{$\begin{array}{l}\text { Adjusted for potential confounding } \\
\text { factors and the child's BMI }\end{array}$} \\
\hline & & & $\operatorname{HR}(95 \% \mathrm{CI})$ & $p$ value & HR $(95 \% \mathrm{CI})$ & $p$ value & HR $(95 \%$ CI $)$ & $p$ value \\
\hline \multirow[t]{2}{*}{ Child $^{\mathrm{f}}$} & \multicolumn{2}{|c|}{ Diabetes cases: $n=41$} & \multicolumn{2}{|c|}{ Diabetes cases: $n=41$} & \multicolumn{2}{|c|}{ Diabetes cases: $n=39$} & \multicolumn{2}{|c|}{ Diabetes cases: $n=34$} \\
\hline & \multicolumn{2}{|c|}{ Total: $n=8,209-8,214$} & \multicolumn{2}{|c|}{ Total: $n=8,209-8,214$} & \multicolumn{2}{|c|}{ Total: $n=7,779-7,784$} & \multicolumn{2}{|c|}{ Total: $n=6,718-6,721$} \\
\hline Any & $24(59)$ & 30 & $2.96(1.58,5.55)$ & 0.001 & $2.84(1.48,5.44)$ & 0.002 & $4.96(2.30,10.68)$ & $<0.001$ \\
\hline Death and illness & $14(34)$ & 16 & $2.45(1.27,4.69)$ & 0.007 & $2.55(1.32,4.95)$ & 0.006 & $2.86(1.42,5.76)$ & 0.003 \\
\hline New family structure & $9(22)$ & 10 & $2.44(1.16,5.11)$ & 0.019 & $2.16(0.99,4.73)$ & 0.055 & $2.32(1.00,5.36)$ & 0.050 \\
\hline Conflict at home & $3(7)$ & 4 & $1.62(0.50,5.25)$ & 0.425 & \multicolumn{2}{|c|}{ No analysis performed } & \multicolumn{2}{|c|}{ No analysis performed } \\
\hline $\begin{array}{l}\text { Interventions from } \\
\text { social services }\end{array}$ & $0(0)$ & 1 & \multicolumn{2}{|c|}{$\begin{array}{l}\text { No cases in exposure } \\
\text { group }\end{array}$} & \multicolumn{2}{|c|}{ No analysis performed } & \multicolumn{2}{|c|}{ No analysis performed } \\
\hline \multirow[t]{2}{*}{ Parent ${ }^{g}$} & \multicolumn{2}{|c|}{ Diabetes cases: $n=55$} & \multicolumn{2}{|c|}{ Diabetes cases: $n=55$} & \multicolumn{2}{|c|}{ Diabetes cases: $n=52$} & \multicolumn{2}{|c|}{ Diabetes cases: $n=47$} \\
\hline & \multicolumn{2}{|c|}{ Total: $n=10,135-10,167$} & \multicolumn{2}{|c|}{ Total: $n=10,135-10,167$} & \multicolumn{2}{|c|}{ Total: $n=9,564-9,595$} & \multicolumn{2}{|c|}{ Total: $n=8,356-8,382$} \\
\hline Any & $34(62)$ & 39 & $2.28(1.32,3.96)$ & 0.003 & $2.40(1.36,4.25)$ & 0.003 & $2.67(1.45,4.92)$ & 0.002 \\
\hline $\begin{array}{l}\text { Death, illness and } \\
\text { accidents }\end{array}$ & $24(44)$ & 27 & $1.88(1.10,3.21)$ & 0.022 & $2.07(1.19,3.59)$ & 0.010 & $2.29(1.29,4.09)$ & 0.005 \\
\hline Conflict & $8(15)$ & 7 & $2.29(1.08,4.86)$ & 0.030 & $1.97(0.88,4.38)$ & 0.098 & $1.86(0.78,4.40)$ & 0.159 \\
\hline Unemployment & $4(7)$ & 6 & $1.17(0.42,3.25)$ & 0.763 & \multicolumn{2}{|c|}{ No analysis performed } & \multicolumn{2}{|c|}{ No analysis performed } \\
\hline
\end{tabular}

${ }^{\mathrm{a}}$ One analysis per exposure variable

${ }^{\mathrm{b}}$ Exposure at time of diagnosis

${ }^{\mathrm{c}}$ Exposures were calculated for children at risk for diabetes but not yet diagnosed. Because the exposure variable is time dependent, proportions are calculated from the frequencies accumulated across all available risk sets. A risk set contains all children still followed and without diabetes (i.e. prior to the time of diagnosis for a child with diabetes)

${ }^{\mathrm{d}}$ Potential confounding factors were heredity for type 1 diabetes, heredity for type 2 diabetes, size for gestational age, the parents' education level and whether the mother worked $\leq 50 \%$ of full time before the child's birth

${ }^{\mathrm{e}} \mathrm{BMI}$ was divided into normal, overweight and obese according to age-adjusted international standards

${ }^{\mathrm{f}}$ Data collections at 5-6,8 and 10-13 years

${ }^{g}$ Data collections at $2-3,5-6,8$ and $10-13$ years

SLEs experienced by the child and the parent were highly correlated (any kind of SLE: at 5-6 years $r=0.56,8$ years $r=$ $0.63,10-13$ years $r=0.63$ ); hence, we tested whether the effect of any kind of SLE experienced by the parent added a unique risk not already captured by an SLE-child of any kind. Adding the variable in a second step in the Cox regression analysis did not add any extra effect beyond the risk for SLEchild $(p=0.585)$.

The significant results regarding experiences of SLE were not found to vary between children with or without type 1 diabetes heredity or between boys and girls after adjusting for heredity and age at entry (ESM Table 3).

A Kaplan-Meier plot of the cumulative incidence of type 1 diabetes in children with and without an experience of SLE, as well as descriptives of time between reporting an SLE and manifest diabetes are shown in ESM Figure 1 and ESM Table 4.

\section{Discussion}

In this population-based prospective study, we found that an SLE experienced by the child at any time during the first 14 years of life increased the risk of diagnosis of type 1 diabetes independent of heredity, heredity for type 2 diabetes, size for gestational age, the parents' education level, whether the mother worked less than $50 \%$ of full time before the child's birth and the childhood BMI. A SLE experienced by the child will probably also be experienced by the parent, and no unique effect was found for experiences of the parent after removing the effects of events experienced by the child. No increased risk was found for parenting stress, parental worries or social support.

In our study, the risk of a child being diagnosed with diabetes before 14 years of age was estimated to be three times higher if the child had experienced an SLE than if they had not. In relation to other environmental factors discussed as risk 
factors, the increase in risk found in our study is comparable to that of factors such as birthweight [4], infant nutrition factors [3] and enterovirus infection [2]. However, when comparing single risk factors, heredity is still much more important. In our study sample, the increase in risk for a child from a family in which another first-degree member has type 1 diabetes (HR 12 ) is about four times higher than the increase in risk associated with an SLE. Nevertheless, psychological stress should be treated as a potential risk factor, and should be examined further in future epidemiological studies, for instance in relation to genetic risk.

A possible mechanism linking SLEs with manifest type 1 diabetes is suggested by the beta cell stress hypothesis [5], which proposes that the child's experience of an SLE could contribute to beta cell stress via increased insulin resistance as well as increased insulin demands due to the physiological stress response, including elevated levels of cortisol. Different dimensions of childhood psychosocial stress have been observed to increase the levels of cortisol [24, 28]. In ABIS, high stress in the family, including the experience of an SLE, has been associated with increased levels of cortisol as well as an increased response to diabetes-associated autoantigens, and also a general imbalance in the immune response [19]. Other studies also indicate that chronic stress can suppress or enhance different parts of the immune responses [29], which may represent another possible mechanism, i.e. that such an imbalance could contribute to an immunological reaction against the beta cells.

High psychological stress levels in the family, including SLE, has in ABIS been associated with an increased risk of obesity [27], which is associated with increased insulin resistance and an increased insulin requirement, causing beta cell stress [5]. However, in the current study the association between SLE and the risk of developing diabetes remained after adjustment for BMI, suggesting that increased BMI is not a major explanation for the findings.

\section{Strengths and limitations of the study}

The use of a population-based cohort, in contrast to a sample selected based on screening for genetic risk (HLA typing), provides unique support for the external validity of our results and enables the generalisation of our results to a general population. The total ABIS sample was representative of Sweden regarding education level [30]. Our dropout was found not to associate with heredity, subsequent diagnosis or the experience of an SLE [31]; therefore, it seems unlikely that our findings are a result of skewed attrition.

The prospective design is a great strength of the study, which makes it possible to look at stress exposure any time in childhood without recall bias due to diagnosis. Despite the prospective design, the self-report checklist of life events that was used involves a degree of retrospective recall that can lead to measurement bias. However, the prospective design probably distributes any possible measurement biases equally between the diabetes cases and non-cases, and thus recall bias is not likely to alter the associations found.

A lack of correspondence between checklist measures of life events and interviews have between pointed out [32, 33]. However, interviews are usually constructed to assess specific events and the experience of that event (e.g. the Life Events and Difficulties Schedule of Brown and Harris [34]), whereas self-report checklists traditionally contains broad categories of events (e.g. The Social Readjustment Rating Scale of Holmes and Rahe [20]). Checklists have been criticised for having large intra-category variability [35], i.e. variability of magnitude and impact on life of the events reported in the same broad category. However, an association with depression was found to be equally high for both a checklist measure and an interview technique $[33,36]$, and it was concluded that checklists can have advantages depending on the purpose of the measurement. In the current study, the checklist was judged adequate when assessing the occurrence of major life events as a proxy for psychological stress. Also, the study design required a large number of participants because measurements had to be obtained through self-report questionnaires.

To maximise power, a statistical method that does not require complete participation was chosen, although power is still low in subanalyses. The method assumes the RR (i.e. HR) for diagnosis is constant over time; however, the impact of a stress exposure probably changes with time since the life event. The most likely violation of the proportional hazard assumption is a reduction in risk through time, which would only result in underestimation of the HR [37].

\section{Comparison with other studies}

Our prospective study confirms the findings from several retrospective studies that observed an association between type 1 diabetes and previous experiences of SLEs [7-17]. Some previous studies found an association with stressful life events in general [9, 10, 14-16], while other studies were more limited to specific events $[7,8,13,17]$, events judged as negative for the child [12] or specific events in a specific age group [11]. However, previous retrospective studies have the methodological shortcoming of recall bias, which has been, for the first time on an individual level, avoided in the current study. In our study, life events including death, illness and accidents in the family were found to separately associate with diagnosis, thus confirming some retrospective studies [7, 8, 11, 13, 16]. However, although the HR was equally high for some of the other categories of life events in our study, the lower proportion of exposed children resulted in a lack of power. Hence, we cannot with any degree of confidence compare the relative importance of specific life events that previous studies 
suggested as risk factors, such as divorce/separation $[7,8,16$, 38], unemployment [16], parental dispute [16] and the trauma of war [17].

Three different time periods have been discussed as important in the development of type 1 diabetes: during immunological development at 0-2 years of age; when the autoimmune reaction starts, as long as 8 years before onset; and the autoimmune process during the year(s) before onset $[12,16]$. In the current study, exposure to psychological stress could have occurred at any time in childhood before diagnosis; in contrast, the majority of the previous retrospective studies investigated exposure in the year(s) shortly before onset [9-17]. Earlier exposure has been investigated, but with inconsistent results $[7,8,10,12,16]$. In ABIS, experience of SLEs early in a child's life has previously been associated with the development of diabetes-related autoantibodies [38, 39], but not with manifest diabetes [18]. Our current results suggest that experience of an SLE at any time in childhood may contribute to manifest diabetes and strengthen the hypothesis that psychological stress can influence the immunological process.

Previously in ABIS, parenting stress occurring when children were 1 year of age was associated with the presence of diabetes-related autoantibodies [39], but not with a diagnosis of type 1 diabetes [18]. The current study that examined parenting stress until children were age 8 years did not find any association with manifest diabetes. Concerning the parent's lack of social support, neither the current study nor a previous study [12] found an association with diagnosis. However, it is reasonable to suppose that both parenting stress and a lack of social support have moderating effects, and thus that children in families with low social support or high parenting stress may be extra vulnerable to stressful experiences.

\section{Conclusions, future research and implications}

Consistent with several previous retrospective studies, this first prospective study concludes that the experience of an SLE (reasonably indicating psychological stress) during the first 14 years of life may be a risk factor for manifest type 1 diabetes. The current study examined SLEs experienced at any time before diagnosis; further studies are thus needed to determine when in the autoimmune process psychological stress may contribute, and in association with which other factors e.g. genetic factors, infections or other periods of pronounced beta cell stress. As experience of stressful life events cannot be avoided, children and their parents should get adequate support to cope with these events to avoid their consequences, which could include medical issues.

Acknowledgements The authors thank the parents for their participation in ABIS. We also thank the staff and the nurses at the 250 well baby clinics and the ABIS research nurses for their help in logistics and data collection.

Parts of the results from this study were presented at ISPAD 2013 (the 39th Annual Conference for International Society for Pediatric and Adolescent Diabetes) and SSSD 2014 (the 49th meeting for The Scandinavian Society for the Study of Diabetes) and published in the conference abstract appendix from ISPAD 2013 [40].

Funding The current work was generously supported by the Swedish Research Council (K2005-72X-11242-11A and K2008-69X-20826-014 ) and the Swedish Child Diabetes Foundation (Barndiabetesfonden). ABIS has also been generously supported by the JDRF Wallenberg Foundation (K 98-99D-12813-01A), Medical Research Council of Southeast Sweden (FORSS) and the Swedish Council for Working Life and Social Research (FAS2004-1775). The funders had no role in the analysis, writing up of results or decision to publish.

Duality of interest The guarantor affirms that this manuscript is an honest, accurate and transparent account of the study being reported; that no important aspects of the study have been omitted; and that any alterations from the study as planned have been explained. The authors declare no conflicts of interest that could have influenced the submitted work.

Contribution statement MN participated in part of the data collection, helped in designing the psychological part of the data collection, planned the statistical analyses, processed and analysed the data and drafted and revised the paper. JC planned and supported the statistical analyses and revised the paper. FK participated in data collection, helped in designing the psychological part of the data collection and revised the paper. JL initiated the ABIS study, designed and monitored the overall data collection, proposed the research question and wrote and revised the paper. AF participated in data collection, designed the psychological part of the data collection and initiated and revised the paper. All authors approved the final version of the paper. $\mathrm{MN}$ is the guarantor of this work.

Availability of data Participant level data are available from the corresponding author at maria.nygren@liu.se. Consent was not obtained but the presented data are anonymised and the risk of identification is low.

\section{References}

1. Atkinson MA, Bluestone JA, Eisenbarth GS et al (2011) How does type 1 diabetes develop?: the notion of homicide or $\beta$-cell suicide revisited. Diabetes 60:1370-1379

2. Tauriainen S, Oikarinen S, Oikarinen M, Hyöty H (2011) Enteroviruses in the pathogenesis of type 1 diabetes. Semin Immunopathol 33:45-55

3. Knip M, Virtanen SM, Åkerblom HK (2010) Infant feeding and the risk of type 1 diabetes. Am J Clin Nutr 91:1506S-1513S

4. Cardwell C, Stene L, Joner G et al (2010) Birthweight and the risk of childhood-onset type 1 diabetes: a meta-analysis of observational studies using individual patient data. Diabetologia 53:641-651

5. Ludvigsson J (2006) Why diabetes incidence increases - a unifying theory. Ann N Y Acad Sci 1079:374-382

6. Patterson C, Guariguata L, Dahlquist G, Soltész G, Ogle G, Silink M (2014) Diabetes in the young - a global view and worldwide estimates of numbers of children with type 1 diabetes. Diabetes Res Clin Pract 103:161-175

7. Stein SP, Charles E (1971) Emotional factors in juvenile diabetes mellitus: a study of early life experience of adolescent diabetics. Am J Psychiatry 128:700-704 
8. Leaverton DR, White CA, McCormick CR, Smith P, Sheikholislam B (1980) Parental loss antecedent to childhood diabetes mellitus. J Am Acad Child Psychiatry 19:678-689

9. Siemiatycki J, Colle E, Campbell S, Dewar RA, Belmonte MM (1989) Case-control study of IDDM. Diabetes Care 12:209-216

10. Vialettes B, Ozanon J, Kaplansky S et al (1989) Stress antecedents and immune status in recently diagnosed type 1 (insulindependent) diabetes mellitus. Diabete Metab 15:45-50

11. Hägglöf B, Blom L, Dahlquist G, Lönnberg G, Sahlin B (1991) The Swedish childhood diabetes study: indications of severe psychological stress as a risk factor for type 1 (insulin-dependent) diabetes mellitus in childhood. Diabetologia 34:579-583

12. Thernlund GM, Dahlquist G, Hansson K et al (1995) Psychological stress and the onset of IDDM in children. Diabetes Care 18:13231329

13. Littorin B, Sundkvist G, Nyström L et al (2001) Family characteristics and life events before the onset of autoimmune type 1 diabetes in young adults: a nationwide study. Diabetes Care 24:1033-1037

14. Vlajinac H, Sipetić S, Marinković J, Bjekić M, Kocev N, Sajić S (2006) The Belgrade childhood diabetes study-comparison of children with type 1 diabetes with their siblings. Paediatr Perinat Epidemiol 20:238-243

15. Sipetić S, Vlajinac H, Marinkovi J et al (2007) Stressful life events and psychological dysfunctions before the onset of type 1 diabetes mellitus. J Pediatr Endocrinol Metab 20:527-534

16. Karavanaki K, Tsoka E, Liacopoulou M et al (2008) Psychological stress as a factor potentially contributing to the pathogenesis of type 1 diabetes mellitus. J Endocrinol Investig 31:406-415

17. Zung A, Blumenfeld $O$, Shehadeh $N$ et al (2012) Increase in the incidence of type 1 diabetes in Israeli children following the Second Lebanon War. Pediatr Diabetes 13:326-333

18. Nygren M, Ludvigsson J, Carstensen J, Sepa Frostell A (2013) Family psychological stress early in life and development of type 1 diabetes: the ABIS prospective study. Diabetes Res Clin Pract 100: 257-264

19. Carlsson E, Frostell A, Ludvigsson J, Faresjö M (2014) Psychological stress in children may alter the immune response. J Immunol 192:2071-2081

20. Holmes TH, Rahe RH (1967) The Social Readjustment Rating Scale. J Psychosom Res 11:213-218

21. Coddington RD (1972) The significance of life events as etiologic factors in the diseases of children. II. A study of a normal population. J Psychosom Res 16:205-213

22. Östberg M, Hagekull B, Wettergren S (1997) A measure of parental stress in mothers with small children: dimensionality, stability and validity. Scand J Psychol 38:199-208
23. Abidin RR (1990) Parenting Stress Index (PSI) manual. Psychological Assessment Resources, Inc, Odessa

24. Koch FS, Ludvigsson J, Sepa A (2010) Parents' psychological stress over time may affect children's cortisol at age 8. J Pediatr Psychol 35: 950-959

25. Crnic KA, Greenberg MT, Ragozin AS, Robinson NM, Basham RB (1983) Effects of stress and social support on mothers and premature and full-term infants. Child Dev 54:209-217

26. Östberg M, Hagekull B (2000) A structural modeling approach to the understanding of parenting stress. J Clin Child Psychol 29:615-625

27. Koch FS, Sepa A, Ludvigsson J (2008) Psychological stress and obesity. J Pediatr 153:839-844

28. Gustafsson PE, Gustafsson PA, Nelson N (2006) Cortisol levels and psychosocial factors in preadolescent children. Stress Health 22:3-9

29. Dhabhar FS (2009) Enhancing vs suppressive effects of stress on immune function: implications for immunoprotection and immunopathology. Neuroimmunomodulation 16:300-317

30. Sepa A, Frodi A, Ludvigsson J (2004) Psychosocial correlates of parenting stress, lack of support and lack of confidence/security. Scand J Psychol 45:169-179

31. Koch FS (2009) Stress and obesity in childhood. Linköping University Linköping, Sweden

32. Monroe SM (2008) Modern approaches to conceptualizing and measuring human life stress. Annu Rev Clin Psychol 4:33-52

33. Lewinsohn PM, Rohde P, Gau JM (2003) Comparability of selfreport checklist and interview data in the assessment of stressful life events in young adults. Psychol Rep 93:459-471

34. Brown GW, Harris TO (1978) Social origins of depression: a study of psychiatric disorder in women. Tavistock Publications, London

35. Dohrenwend BP (2006) Inventorying stressful life events as risk factors for psychopathology: toward resolution of the problem of intracategory variability. Psychol Bull 132:477-495

36. Duggal S, Malkoff-Schwartz S, Birmaher B et al (2000) Assessment of life stress in adolescents: self-report vs interview methods. J Am Acad Child Adolesc Psychiatry 39:445-452

37. Schemper M (1992) Cox analysis of survival data with nonproportional hazard functions. Statistician 41:455-465

38. Sepa A, Frodi A, Ludvigsson J (2005) Mothers' experiences of serious life events increase the risk of diabetes-related autoimmunity in their children. Diabetes Care 28:2394-2399

39. Sepa A, Wahlberg J, Vaarala O, Frodi A, Ludvigsson J (2005) Psychological stress may induce diabetes-related autoimmunity in infancy. Diabetes Care 28:290-295

40. Nygren M, Carstensen J, Koch F, Frostell A, Ludvigsson J (2013) ISPAD 2013 oral sessions: O42 experiences of a stressful life event increases the risk for childhood type 1 diabetes: the ABIS populationbased prospective cohort study. Pediatr Diabetes 14(Suppl 18):36 